\title{
Study of Anxiety, Stress and Depression among Flood Affected People in Kashmir Valley
}

\author{
Dr. R. Sankar ${ }^{1}$, Wani M. Amin ${ }^{2} *$
}

\section{ABSTRACT}

This research paper is an attempt to study the level of anxiety, stress and depression among flood affected people in Kashmir valley. This study is based on sample of 100 subjects divided into two equal groups (male and female) selected through sample random sampling. The level of anxiety, stress and depression were measured by anxiety, depression and stress scale (ADSSBSPSA) developed by Pallavi Bhatnagar et al., Department of Psychology Lucknow University. Mean, S.D, SED and t-test were applied for data analysis. The results reveal that the significant difference was found between the male and female subjects in respect to anxiety, stress and depression scores. Significant difference was found at 0.05 and 0.01 levels respectively.

Keywords: Anxiety, Depression, Stress, flood and Gender

In September 2014 (Paradise on earth), the Kashmir valley witnessed the devastating flood across many of its districts (Srinagar, Anantnag, Baramulla, Pulwama, Ganderbal, Kulgam and Budgam) caused by torrential rainfall from $2^{\text {nd }}$ September. This flood was recognized as the worst flood in 50 years (Reports claim that it was the worst flood in 109 years). About 5 million people were affected in 2600 villages in the entire state out of which 400 villages in Kashmir were completely submerged. Around 281 people died in these floods 196 of them in the Jammu province and 85 in the Kashmir Valley, 12.50 lakh families were directly or indirectly affected by the floods. The flood washed residential houses, schools, colleges, hospitals, paddy fields, orchards, government establishments and businesses units' property of 1, 00,000 crores was damaged. Up to 5 days Kashmir valley was cut off from the world. There was no any communication in the valley Radio, Television, Mobile, Internet etc was not working. As many as 60 major and minor roads were cut off and over 60 bridges washed away. $300 \mathrm{~km}$ long Srinagar Jammu national highway was closed to vehicular traffic for more 10 days due to landslides and floods in different parts of Kashmir.

\footnotetext{
${ }_{1}^{1}$ Assistant Professor Department of Psychology Annamalai University Tamil Nadu, India

${ }^{2}$ Ph.D Research Scholar of Psychology Annamalai University Tamil Nadu, India

*Responding Author

(C) 2016 I R Sankar, W Amin; licensee IJIP. This is an Open Access Research distributed under the terms of the Creative Commons Attribution License (http://creativecommons.org/licenses/by/2.0), which permits unrestricted use, distribution, and reproduction in any Medium, provided the original work is properly cited.
} 


\section{Study of Anxiety, Stress and Depression among Flood Affected People in Kashmir Valley}

Flood not only damage properties and belongings of people but also loss of life. Loss of loved one will have a very significant effect on the victims especially if it involved people who are very close to them. After the death of loved one a person shows the response of sadness and a feeling of loss for a period of a few months to a year. Some people show chronic sadness which is called complicated grief that is the inability to accept death of beloved person.

Depressed flood victim in Kashmir experience emotional disturbance which is in the form of sadness, hopelessness and lack of interest in the world around him. Death of a loved one, loss of properties and belongings, loss of shelter, caused by flood will lead to all sort of stress if treatment action is not done.

The recent disastrous floods in valley undoubtedly lead to increased mental health problems; people experience various psychological problems like post-traumatic stress disorders (PTSD), adjustment disorders, anxiety disorders, depression, etc.

Psychologists in Kashmir believes that the devastating floods have increased the levels of anxiety, stress disorders and depression among the people particularly children. Dr. Aijaz said "Post floods we have seen an increase in anxiety and depression among people in valley. The images of trauma and chaos which prevailed during floods are still fresh in peoples' minds. People witnessed deaths of their loved ones. People went through mayhem. They were rendered homeless. Some one's house was destroyed, someone's business was devastated, and scores of families were rendered financially weak. This is something which is not easily forgettable and it has caused stress and trauma among people. Children have been more vulnerable to it," He added, "It was a totally disturbing situation and this is going to affect the psychological stability of a person who went through all this. I can say that anxiety disorders have increased among the worst affected people. Therefore, off late we are witnessing a rise on trauma related problems." Dr. Arshid Associate Professor, Department of Psychiatry, GMC Srinagar said that "We have a significant number of patients who suffer from mental disorders like depression, anxiety etc. But the most common has been post traumatic stress disorder. Kashmir valley has been through a very dreadful phase" Dr Waseem psychiatrist in valley said "Earlier we were treating PTSD patients who were victims of the turmoil in the Valley. There were patients who had seen their loved ones die or the people who themselves have had close shave with death. But now we are treating patients who are witness to the ordeal caused by the floods,"

After the 2014 floods in Kashmir there is a tremendous increase in psychiatric problems in the valley. According to official data since January 2015 in Psychiatry OPDs of GMC Srinagar 1, 30,000 patients were seen out of them 75,000 patients were seen at Institute of Mental Health and Neurosciences Badamwari and 55,000 patients visited SMHS Community Center among them more than $50 \%$ of the patients were females. 


\section{Study of Anxiety, Stress and Depression among Flood Affected People in Kashmir Valley}

Research has shown that natural disasters like floods, earthquakes, cyclones, tsunami etc not only causes physical abnormalities and property damage but they directly affect the psychological health and wellbeing. Natural disasters are the prone for anxiety disorders, post traumatic stress disorder and mood disorders. Tapsell (2001) found stress, anxiety, fainting, panic attacks, depression, lethargy and agoraphobia among flood affected people. Shirley et al., (2009) investigated the risk of posttraumatic stress disorder and depression in survivors of the floods in Bihar. They found that people over the age of 60 years had significantly higher scores for PTSD and depression compared to all groups. Elizabeth et al., (2000) found that anxiety and depression among victims are related to losses in the event of flooding. Phifer (1990) conducted a study on Psychological distress and somatic symptoms after natural disaster. Results revealed that flood exposure was associated with significant increases in depression and anxiety. Liu et al., (2006), Mason et al., (2010), Norris et al., (2005) investigated that mental health disorders are commonly found in people affected by natural disasters such as floods are post-traumatic stress disorder (PTSD), followed by depression and anxiety. Wani (2015) found significant difference between the mean scores of mental health in respect to gender and marital status. Nasir et al., (2012) investigated Psychological effects on victims of the Johor flood. Results revealed that flood victims suffered cognitive, emotional and behavioral shortfalls such as fear, anxiety, hopelessness, helplessness and depression. Mandler \& Watson, (1966) investigated that anxieties among flood victims can cause stress, fear and restlessness. Kaplan (1983) revealed that the flood disrupts normal life and activities results adaptive behavior and psychological disorder. Davidson (2001, 2004) in his study found that women were two times (10-14\% PTSD) more likely to develop PTSD than men (5-6\% PTSD).

\section{METHODOLOGY}

Statement of the problem: - To study the level of anxiety stress and depression among flood affected people in Kashmir valley.

\section{Objectives}

1. To find the level of anxiety among male and female subjects.

2. To find the level of stress among male and female subjects.

3. To find the level of depression among male and female subjects.

\section{Hypotheses:}

1. There is significant difference found between the anxiety scores of male and female subjects.

2. There is significant difference found between the stress scores of male and female subjects.

3. There is significant difference found between the depression scores of male and female subjects

\section{Variables:}

An experimental variable is gender (Male and Female) and criterion variables are anxiety, stress and depression in the present study. 


\section{Sample:}

In the present study the investigator take sample of 100 subjects equally divided into two groups (male and female) selected through sample random sampling method in district Srinagar.

\section{Measuring tool:}

Anxiety, Depression and Stress scale (ADSS-BSPSA) developed by Pallavi Bhatnagar, Megha Singh, Manoj Pandey, Sandhya and Amitabh Department of Psychology Lucknow University was used for data collection. The scale comprises of 48 items divided into 3 subscales which are Anxiety subscale consists of 19 items, Depression subscale consists of 15 items and Stress subscale consists of 14 items. Each item is scored 1 for "Yes" and 0 for "No" response.

The reliability of the total scale is measured by Cronbach's Alpha and Spearman-Brown coefficient found 0.81 and 0.89 respectively. The obtained reliability for Anxiety, Depression and Stress subscales as measured by Cronbach's Alpha is 0.76, 0.75 and 0.61 and by Spearman Brown coefficient is $0.86,0.86$ and 0.76 respectively.

\section{RESULTS}

The aim and objectives of the present study was to find the level of anxiety, stress and depression among people affected by flood in Kashmir. The sample of 100 subjects selected through sample random sampling method. The whole data was obtained by using Anxiety, Depression and Stress scale (ADSS-BSPSA) developed by Pallavi Bhatnagar, Megha Singh, Manoj Pandey, Sandhya and Amitabh Department of Psychology Lucknow University. The scores were assigned for different responses according to the item. The scores were arranged in tabular form and then ttest was applied to calculate the data. Mean and S.D and $S E_{D}$ value of every group was also calculated. Results are given in tables

Table 1, Showing Mean, S.D, $S E_{D}$ and $t$-value of anxiety scores of male and female subjects

\begin{tabular}{|l|l|l|l|l|l|l|l|}
\hline Group & Total scores & $\mathbf{N}$ & Mean & $\boldsymbol{\sigma}$ & SE $_{\mathbf{D}}$ & Df & t-value \\
\cline { 1 - 5 } Male & 650 & 50 & 13 & 3.89 & 0.81 & 98 & $2.46^{*}$ \\
\cline { 1 - 4 } & 550 & 50 & 11 & 4.25 & & & \\
\hline
\end{tabular}

*significant at 0.05 level

Table 2, Showing Mean, S.D, $S E_{D}$ and $t$ - value of stress scores of male and female subjects

\begin{tabular}{|l|l|l|l|l|l|l|l|}
\hline Group & Total scores & $\mathbf{N}$ & Mean & $\boldsymbol{\sigma}$ & $\mathbf{S E}_{\mathbf{D}}$ & $\mathbf{D f}$ & t-value \\
\hline Male & 499 & 50 & 10 & 1.67 & 0.40 & 98 & $4.5^{* *}$ \\
\cline { 1 - 5 } & 410 & 50 & 8.2 & 2.37 & & & \\
\hline
\end{tabular}

**significant at 0.01 level

Table3, Showing Mean, S.D, $S E_{D}$ and t- value of depression scores of male and female subjects

\begin{tabular}{|l|l|l|l|l|l|l|l|}
\hline Group & Total scores & $\mathbf{N}$ & Mean & $\boldsymbol{\sigma}$ & SE $_{\mathbf{D}}$ & Df & t-value \\
\hline Male & 435 & 50 & 8.7 & 2.28 & 0.38 & 98 & $5.15^{* *}$ \\
\cline { 1 - 3 } & 337 & 50 & 6.74 & 1.96 & & & \\
\hline
\end{tabular}

**significant at 0.01 level 


\section{DISCUSSION}

The main objective of the study was to study the level of anxiety, stress and depression among flood affected people in Kashmir. For this purpose data was collected in Srinagar district which was badly affected by the flood in 2014. The results of the present study suggested that there is significant difference between the mean scores of anxiety, stress and depression.

From the table 1, it is clear that there is significant difference between the anxiety scores of male and female subjects as our obtained $t$ value (2.46) with df 98 is found significant at 0.05 level of significance. The obtained mean score of anxiety of male subjects $(M=13$, S.D. = 3.89) is significantly higher than the mean score of female subjects $(\mathrm{M}=11$, S.D. $=4.25)$ with $\mathrm{SE}_{\mathrm{D}} 0.81$. On the basis of our findings we may say that our hypothesis there is significant difference found between the anxiety scores of male and female subjects is accepted.

By analyzing Table 2, it appears that the obtained mean score of stress of male subjects $(\mathrm{M}=10$, S.D. = 1.67) is significantly higher than the mean score of female subjects (M=8.2, S.D. =2.37) and the $\mathrm{SE}_{\mathrm{D}}$ is found 0.40 . The obtained t value (4.5) with df 98 is found significant at 0.01 level of significance. Thus our hypothesis there is significant difference found between the stress scores of male and female subjects is accepted. Our findings are also supported by the study of Affizal \& Nurul (2014) who investigated stress and depression between men and women. Results revealed that stress and depression showed significant association in both male and female inmates.

The table 3 shows the mean, S.D, $\mathrm{SE}_{\mathrm{D}}$ and $\mathrm{t}$ value of depression scores among male and female subjects. The obtained mean score of male subjects $(M=8.7$, S.D. $=2.28)$ is significantly higher than the mean score of female subjects ( $M=6.7$, S.D. 1.96) and the $S E_{D}$ is found 0.38. The obtained t value (5.15) with df 98 is found significant at 0.01 level of significance. Thus our hypothesis there is significant difference found between the depression scores of male and female subjects is accepted. Our findings are also supported by Khodidas (2013) who also found significant different between the depression level among male and female aged persons was significant with 0.01 level. Katragadda \& Tidwell (1998) revealed that females had the highest percentage (31.2\%) of moderate to severe depression. Results also show that females show more depressive symptoms than males.

\section{CONCLUSIONS}

To sum up taking into account the results of the current study, we might conclude that there is significant difference between the anxiety, stress and depression among flood affected people in Kashmir valley. Since 1989 the valley has witnessed a significant increase in psychological disorders like anxiety, stress and depression due to conflict. Moreover, the devastating floods in 2014 also given rise to stress and anxiety disorder among people more than 1 lakh patients were seen in the Psychiatry OPDs of GMC Srinagar since January 2015 which is alarming. We all should join hands to help the people in such situations government as well as NGO's should come forward to provide psychological services to people free of cost as flood also cause huge 
economical damage. Also Psychologists, Psychology students should come forward to provide evidence based strategies to people to facilitate their recovery, so people in paradise will definitely raise again above all odds and pains.

\section{REFERENCES}

Affizal A., Nurul H., M., (2014). Stress and depression: A comparison study between men and women inmates in peninsular Malaysia. International journal of humanities and social science, 4 (2): 153.

Ahmed M (2014). Over 100 dead, 2600 villages submerged as floods ravage Kashmir. Rediff News.

Davidson (2001). Recognition and treatment of posttraumatic stress disorder. JAMA, 286(5), 584-588.

Davidson (2004). Long-term treatment and prevention of posttraumatic stress disorder. Journal of Clinical Psychiatry, 65 (1):44-48.

Elizabeth, M., G., Karen, W., Samuel, J., S., (2000). Natural disaster and depression: A prospective investigation of reactions to the 1993 Midwest floods. American Journal of Community Psychology, 28 (4).

Farzana Syed (2015). Psychological disorders on rise in valley. Kashmir Times Newspaper. Thursday, April 16, 2015.

Kaplan, H. B. (1983). Psychosocial Stress Trends in Theory and Research. New York: Academic Press.

Katragadda, C., P., Tidwell, R., (1998). Rural Hispanic adolescents at risk for depressive symptoms. Journal of Applied Social Psychology, 28(20), 1916-1930.

Khodidas N., Z., (2013). A comparative study of depression among male and female aged persons. International Multidisciplinary Journal of Applied Research, 1(3):36-37.

Liu, A., Tan, H., Zhou, J., Li, S., Yang, T., Wang, J. (2006). An epidemiologic study of posttraumatic stress disorder in flood victims in Hunan China. Canadian Journal of Psychiatry,51:350-354.

Mandler, G., Watson, D. (1966). Relationship between locus of control and anxiety. Journal of Personality and Social Psychology, 6, (1):91-92.

Mason, V., Andrews, H, Upton, D., (2010). The psychological impact of exposure to floods. Psychological Health Medican, 15:61-73.

Nasir R., Zainah, A., Khairud R., (2012). Psychological effects on victims of the Johor flood. Asian Social Science, 8, (8):126-133.

Norris, F., Baker, C, Murphy, A, Kaniasty, K., (2005). Social support mobilization and deterioration after Mexico’s 1999 flood: effects of context, gender, and time. American Journal of Community Psychology. 36:15-28.

Phifer, J., F. (1990). Psychological distress and somatic symptoms after natural disaster: Differential vulnerability among older adults. Psychology and Aging, 5:412-420. 
Shirley T., Nilkamal S., Meesha J. (2009). Risk of posttraumatic stress disorder and depression in survivors of the floods in Bihar, India. Indian Journal of Medical Science, 63, (8):330334.

Tapsell, S. (2001). The hidden impacts of flooding: experiences from two English communities. Integrated water resources management (proceedings of a symposium held at Davis, California, April 2000), IAHS, No. 272.

The North lines Newspaper (2014) Stress disorder rising among flood-affected people in Kashmir, 12 (259).

Wani, M., A., (2014). Study of mental health among the people affected by terrorism in Kashmir. International Journal of Social Science and Language, 1(1): 67-72.

Zehru Nissa (2015). 1, 30,000 patients seen at Psychiatry OPDs of GMC this year doctors pitch for more attention on mental health. Greater Kashmir News Paper Srinagar. Tuesday, Oct 212015. 